Article

\title{
Synthesis of Silver Nanoparticles in Chitosan, Gelatin and Chitosan/Gelatin Bionanocomposites by a Chemical Reducing Agent and Their Characterization
}

\author{
Mansor Bin Ahmad *, Jenn Jye Lim, Kamyar Shameli, Nor Azowa Ibrahim and Mei Yen Tay \\ Department of Chemistry, Faculty of Science, Universiti Putra Malaysia, UPM Serdang, Selangor \\ 43400, Malaysia; E-Mails: jennjye87@yahoo.com (J.J.L.); kamyarshameli@gmail.com (K.S.); \\ norazowa@science.upm.edu.my (N.A.I.); tmyen_87@hotmail.com (M.Y.T.)
}

* Author to whom correspondence should be addressed; E-Mail: mansorahmad@science.upm.edu.my; Tel.: +603-89466044; Fax: +603-89466043.

Received: 23 June 2011; in revised form: 20 July 2011 / Accepted: 3 August 2011 /

Published: 25 August 2011

\begin{abstract}
In this research, silver nanoparticles (AgNPs) were synthesized in chitosan (Cts), Cts/gelatin and gelatin suspensions using a chemical reducing agent. Cts and gelatin were used as natural stabilizers and solid support, whereas $\mathrm{AgNO}_{3}$ was used as the silver precursor. Sodium borohydride $\left(\mathrm{NaBH}_{4}\right)$ was used as the reducing agent. The properties of AgNPs in Cts, Cts/gelatin and gelatin bionanocomposites (BNCs) were studied in terms of their surface plasmon resonance, crystalline structure, average diameter size, particle distributions, surface topography and functional groups. All the samples were characterized by UV-visible spectroscopy, powder X-ray diffraction, transmission electron microscopy, atomic force microscopy and Fourier transform infrared spectroscopy.
\end{abstract}

Keywords: chitosan; gelatin; silver; bionanocomposite; chemical reduction method

\section{Introduction}

The field of nanotechnology has emerged as one of the most active areas of research in materials science over the last decades. The fact that nanoparticles (NPs) exhibit quite a number of interesting and unique properties based on their specific characteristics, such as size, distribution and morphology leads itself to various applications [1], for instance in catalysis, microelectronics, sensors [2], 
biomaterials, therapeutics [3] as well as antimicrobial [4] applications. The term nanocomposite was derived to define filled polymers containing dispersed nanoparticles. Based on the definition, another term has been derived which is bionanocomposites (BNCs). BNCs are made of a natural polymeric matrix and inorganic/organic filler with at least one dimension on the nanometer scale. Metal/polymer compounds such as BNCs are becoming a promising new research field for their unique properties [5].

During the preparation of silver nanoparticles (AgNPs), stabilizers are one kind of agent that should be present and that play an important role in controlling the formation of nanoparticles, as well as their dispersion stability. Polymers are often used as particle stabilizers due to the fact that they are effective in preventing agglomeration and precipitation of the particles. This is important in synthesizing nanoparticles with homogenous distributions. Various methods have been introduced to synthesize $\mathrm{Ag}$ nanocomposites, including photochemical [5-7], chemical [3,8], microwave [9], sono-chemical $[10,11]$, and radiochemical reducing methods [12,13]. Synthesis of AgNPs using different methods has been carried out with increasing frequency. This further supports the fact this field is currently receiving a lot of attention. Some examples of composites being synthesized include AgNPs with polymers such as poly(vinylalcohol) [14], poly(vinylpyrolidone) [13,15], polymethylmethacrylate [16], poly(lactic acid) [17], poly(methyl vinyl ether) [18] chitosan [19,20], gelatin [21] etc. This accounts for the different properties of composites that are synthesized, which allow them to serve different purposes in our daily life.

Chitosan (Cts) is a polysaccharide that occurs naturally. Its units are composed of randomly distributed $\beta$-(1-4)-linked D-glucosamine (deacetylated unit) and $N$-acetyl-D-glucosamine (acetylated unit). Cts has been investigated as a natural cationic biopolymer because of its known excellent biocompatibility, biodegradability, nontoxicity, bioactivity, and multifunctional groups from years of research. It is also extensively being studied for food packaging film, bone substitutes, artificial skin, biomedical applications and $\mathrm{pH}$ sensitive drug delivery among others due to a number of great properties it possesses [22].

Gelatin is made up of a mixture of peptides and proteins produced by partial hydrolysis of naturally occurring collagen. The carboxyl groups on its chain backbones are one of its amazing features that enables the possibility to form hydrogen bonds with chitosan for a well-mixed hybrid [23]. Besides, the fact that it is used in pharmaceuticals, cosmetic manufacturing among others prove that it is perfectly non-toxic to human. This explains the preferable usage of gelatin in research work as potential side effects of compounds synthesized from it as precursor can be reduced to a minimum.

Here, we report synthesis of AgNPs by chemical reduction method using $\mathrm{NaBH}_{4}$. Cts, Cts/gelatin and gelatin suspension were used with the original intention to prevent aggregation of AgNPs. In addition, these matrixes were found to be functioning as stabilizer also in later stage of experiment. The size of the silver nanoparticles synthesized is less than $15 \mathrm{~nm}$.

\section{Results and Discussion}

In this research, $\mathrm{Cts}$, Cts/gelatin and gelatin suspension were used as the stabilizers for reducing $\mathrm{AgNO}_{3}$ using $\mathrm{NaBH}_{4}$ as strong reducing agent. As a result, $\mathrm{AgNO}_{3}$ was successfully reduced by $\mathrm{NaBH}_{4}$ in the presence of Cts/gelatin or either one, resulting in the formation of AgNPs according to the following equations (1-3) [24]: 


$$
\begin{aligned}
\mathrm{Ag}^{+} / \mathrm{Cts}+\mathrm{BH}_{4}^{-}+3 \mathrm{H}_{2} \mathrm{O} & \rightarrow \mathrm{Ag}^{0} / \mathrm{Cts}+\mathrm{B}(\mathrm{OH})_{3}+3.5 \mathrm{H}_{2} \\
\mathrm{Ag}^{+} / \text {Cts } / \text { gelatin }+\mathrm{BH}_{4}^{-}+3 \mathrm{H}_{2} \mathrm{O} & \rightarrow \mathrm{Ag}^{0} / \mathrm{Cts} / \text { gelatin }+\mathrm{B}(\mathrm{OH})_{3}+3.5 \mathrm{H}_{2} \\
\mathrm{Ag}^{+} / \text {gelatin }+\mathrm{BH}_{4}^{-}+3 \mathrm{H}_{2} \mathrm{O} & \rightarrow \mathrm{Ag}^{0} / \text { gelatin }+\mathrm{B}(\mathrm{OH})_{3}+3.5 \mathrm{H}_{2}
\end{aligned}
$$

As shown in Figure 1, the $\mathrm{AgNO}_{3} / \mathrm{Cts} /$ gelatin suspensions ( $\left.\mathrm{S} 0\right)$ were colorless. After the addition of the reducing agent to the suspensions, they turned dark brown (S1-S3) indicating the formation of AgNPs in the Cts, Cts/gelatin and gelatin suspensions. The formation of AgNPs was also followed by measuring the surface plasmon resonance bands of the $\mathrm{AgNO}_{3} / \mathrm{Cts} /$ gelatin (S0), $\mathrm{Ag} / \mathrm{Cts}(\mathrm{S} 1$ ), $\mathrm{Ag} / \mathrm{Cts} /$ gelatin (S2) and Ag/gelatin (S3) suspensions at wavelengths within the range of 300-700 nm (Figure 2). The PXRD patterns in the wide angle range of $2 \theta\left(5^{\circ}<2 \theta<90^{\circ}\right)$ were also detected for the crystalline structures determination of the synthesized Ag NPs (Figure 3).

Figure 1. Photograph of $\mathrm{AgNO}_{3} / \mathrm{Cts} /$ gelatin (S0), $\mathrm{Ag} / \mathrm{Cts}$ (S1), Ag/Cts/gelatin (S2) and $\mathrm{Ag} /$ gelatin (S3) bionanocomposite suspensions.

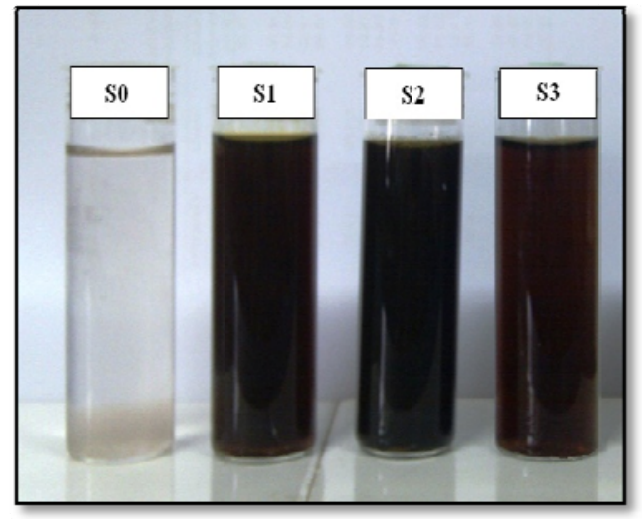

Figure 2. Ultraviolet-visible absorption spectra of $\mathrm{AgNO}_{3} / \mathrm{Cts} /$ gelatin ( $\left.\mathrm{S} 0\right), \mathrm{Ag} / \mathrm{Cts}$ (S1), $\mathrm{Ag} / \mathrm{Cts} /$ gelatin (S2), and Ag/gelatin (S3) BNCs suspension after few hours (A); and after four months (B).
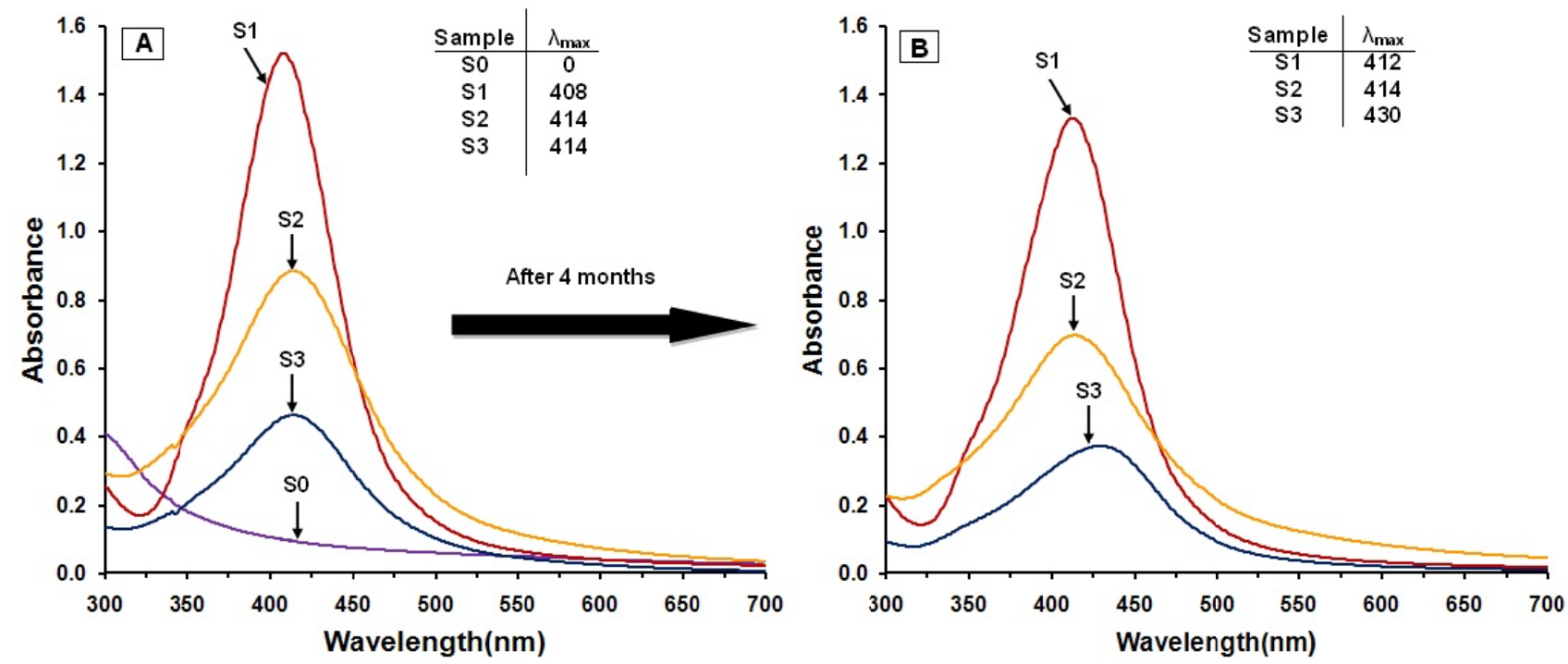
Figure 3. Powder X-ray diffraction patterns of $\mathrm{Ag} / \mathrm{Cts}(\mathrm{S} 1), \mathrm{Ag} / \mathrm{Cts} /$ gelatin (S2) and $\mathrm{Ag} /$ gelatin (S3) BNCs for its crystals structure determination.

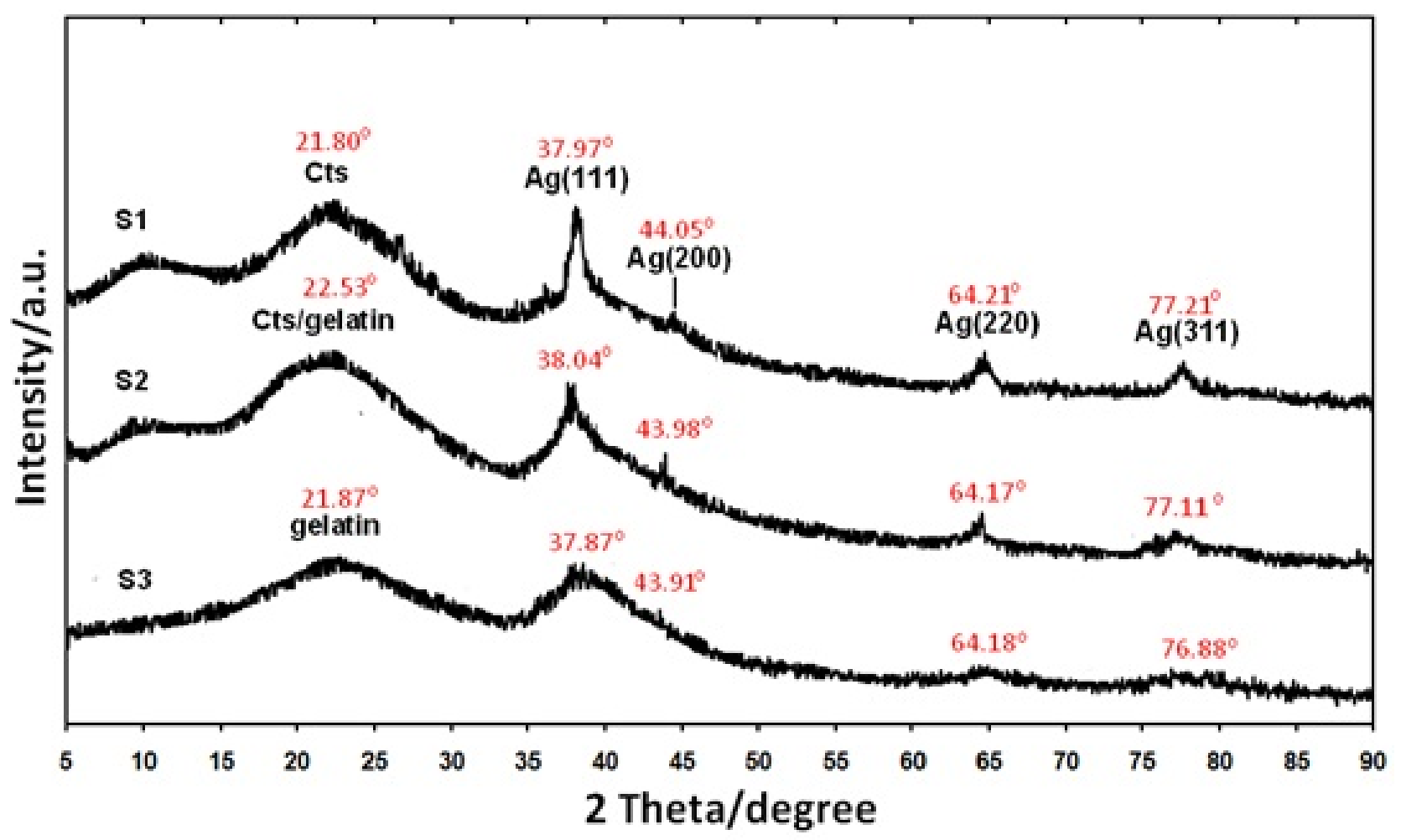

The TEM images and size distribution of the AgNPs showed that the mean diameter of the nanoparticles ranged from about $3.37 \mathrm{~nm}$ to $10.50 \mathrm{~nm}$ (Figure 4). As shown in Figure 5, the AFM images show additional information for the nanoparticles size detection. The chemical structures of pure polymers and AgBNCs were analyzed by FTIR spectroscopy (Figuress 6 and 7).

\subsection{Ultraviolet-Visible Spectroscopy}

The color of the $\mathrm{AgNO}_{3} / \mathrm{Cts} /$ gelatin suspensions which undergo the $\mathrm{NaBH}_{4}$ reduction process changed from colorless to dark brown. These color changes indicated that the AgNPs were formed in the $\mathrm{Cts}, \mathrm{Cts} /$ gelatin and gelatin suspension. This statement is further proven by UV-visible spectrum in Figure 2A. No absorption band is observed in the $300-500 \mathrm{~nm}$ range for $\mathrm{AgNO}_{3} / \mathrm{Cts} /$ gelatin, showing that no AgNPs formation has occurred in the sample. After the addition of $\mathrm{NaBH}_{4}$, surface plasmon resonance bands were detected around 408-414 nm, indicating the formation of AgNPs. These absorption bands were an indication that the diameters of the AgNPs were small [25]. These results were further confirmed with the TEM data, revealing the diameter of the AgNPs. The absorption peak of $\mathrm{Ag}$ for $\mathrm{Ag} / \mathrm{Cts} \mathrm{BNC}$ suspension with value of $408 \mathrm{~nm}$ was red-shifted to a higher wavelength (414 nm) in Ag/Cts/gelatin and $\mathrm{Ag} /$ gelatin sample. The SPR absorption band and TEM results showed signs of an exceptional case: as size decreases from $d=10.50 \mathrm{~nm}$ it blue-shifts, but then turns over near $\mathrm{d}=3.37$ and $4.38 \mathrm{~nm}$ and it red-shifts. It could be explained by the Mie theory model which indicates that the reason of the red-shift is the lowered conductivity in the outer metallic layer caused by chemical interactions [26]. For the stability test of the AgNPs, absorption spectra of the samples were measured after storage for four months (Figure 2B). The absorption peaks of the Ag NPs in S1 
and S3 shift slightly from 408 to $412 \mathrm{~nm}$ and 414 to $430 \mathrm{~nm}$ respectively, whereas the absorption peak for the S2 remains the same at $414 \mathrm{~nm}$. Overall, the spectra for all the samples showed no significant changes in either their intensity or spectral shape [27].

Figure 4. Transmission electron microscopy images and corresponding particle size distributions of $\mathrm{Ag} / \mathrm{Cts}(\mathbf{A}, \mathbf{B}), \mathrm{Ag} / \mathrm{Cts} /$ gelatin $(\mathbf{C}, \mathbf{D})$ and $\mathrm{Ag} /$ gelatin $(\mathbf{E}, \mathbf{F})$ BNCs.
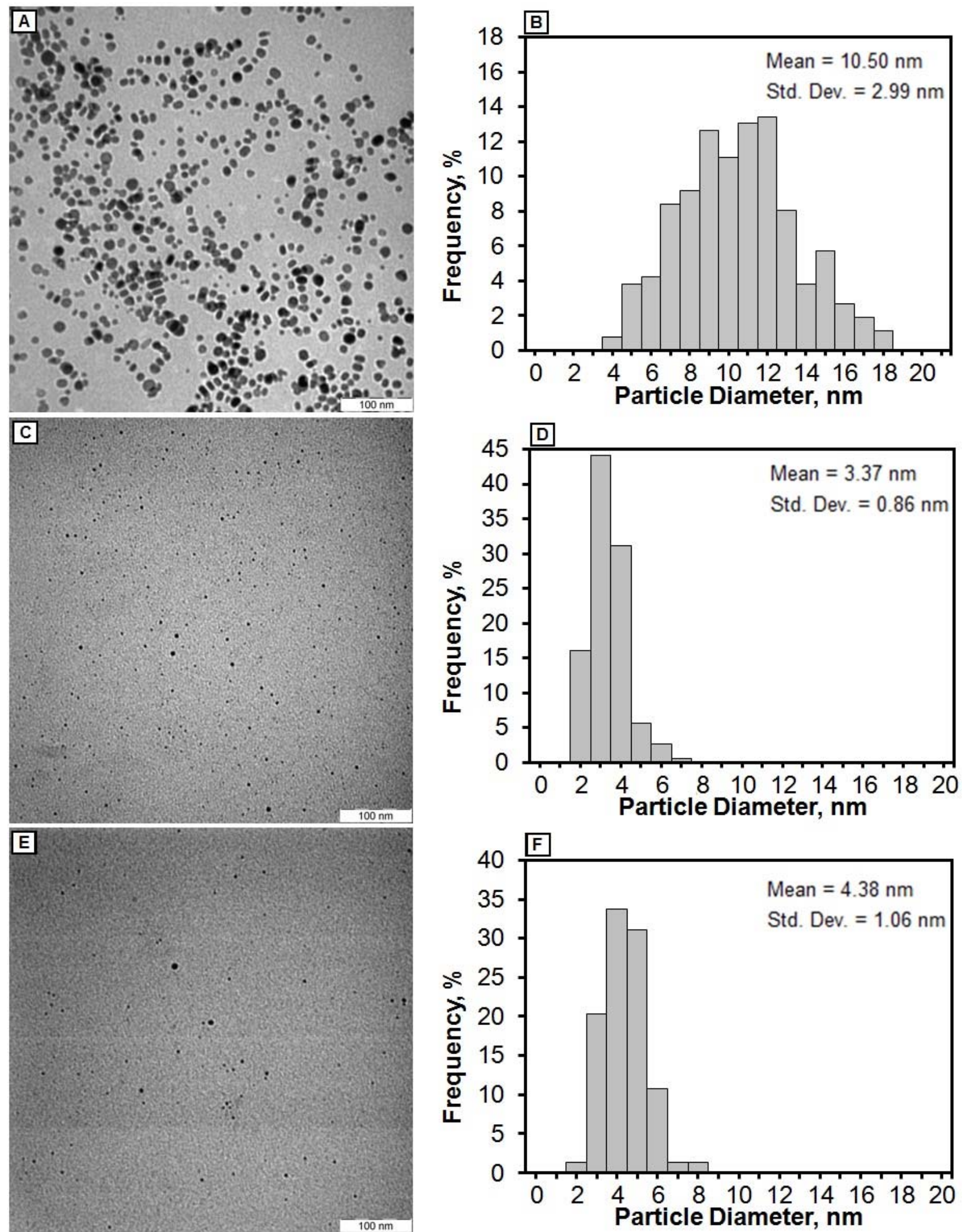
Figure 5. AFM images of the surface topography of $\mathrm{Ag} / \mathrm{Cts}(\mathbf{A}) ; \mathrm{Ag} / \mathrm{Cts} /$ gelatin (B); and $\mathrm{Ag} /$ gelatin $(\mathbf{C})$ thin films.
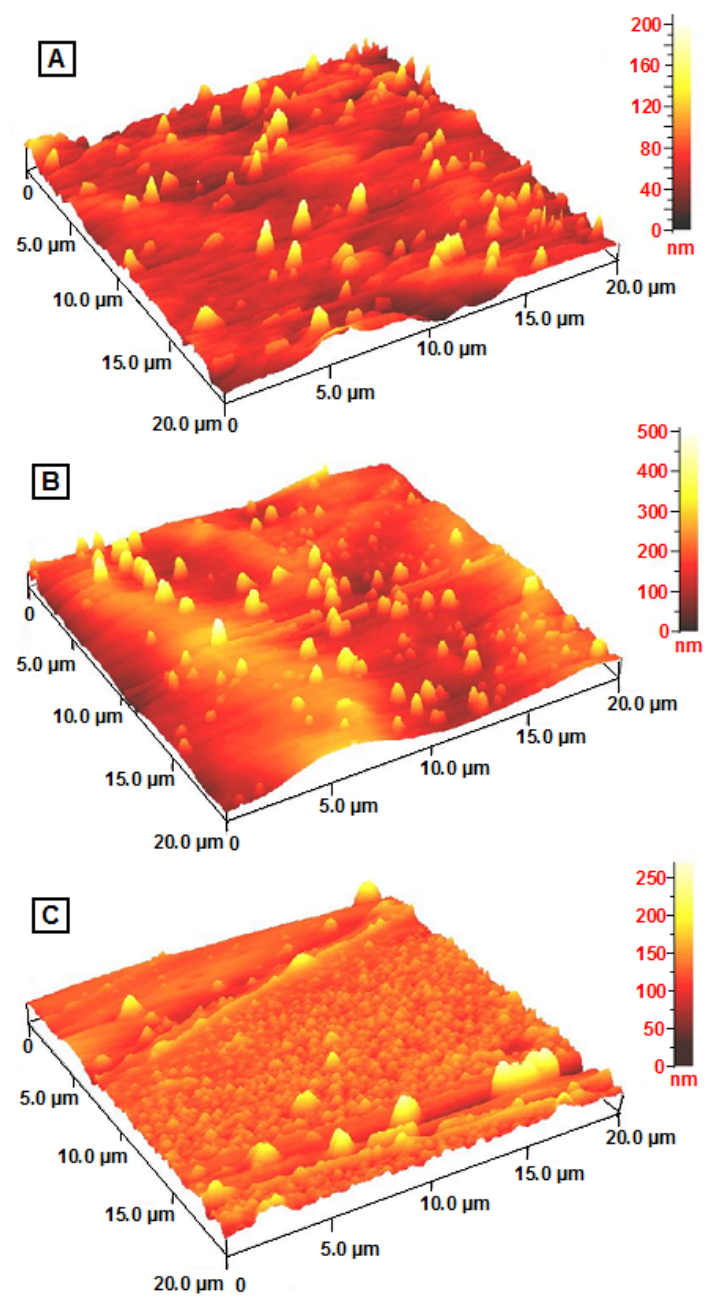

Figure 6. Fourier transform infrared spectra of Cts, Cts/gelatin, and gelatin.

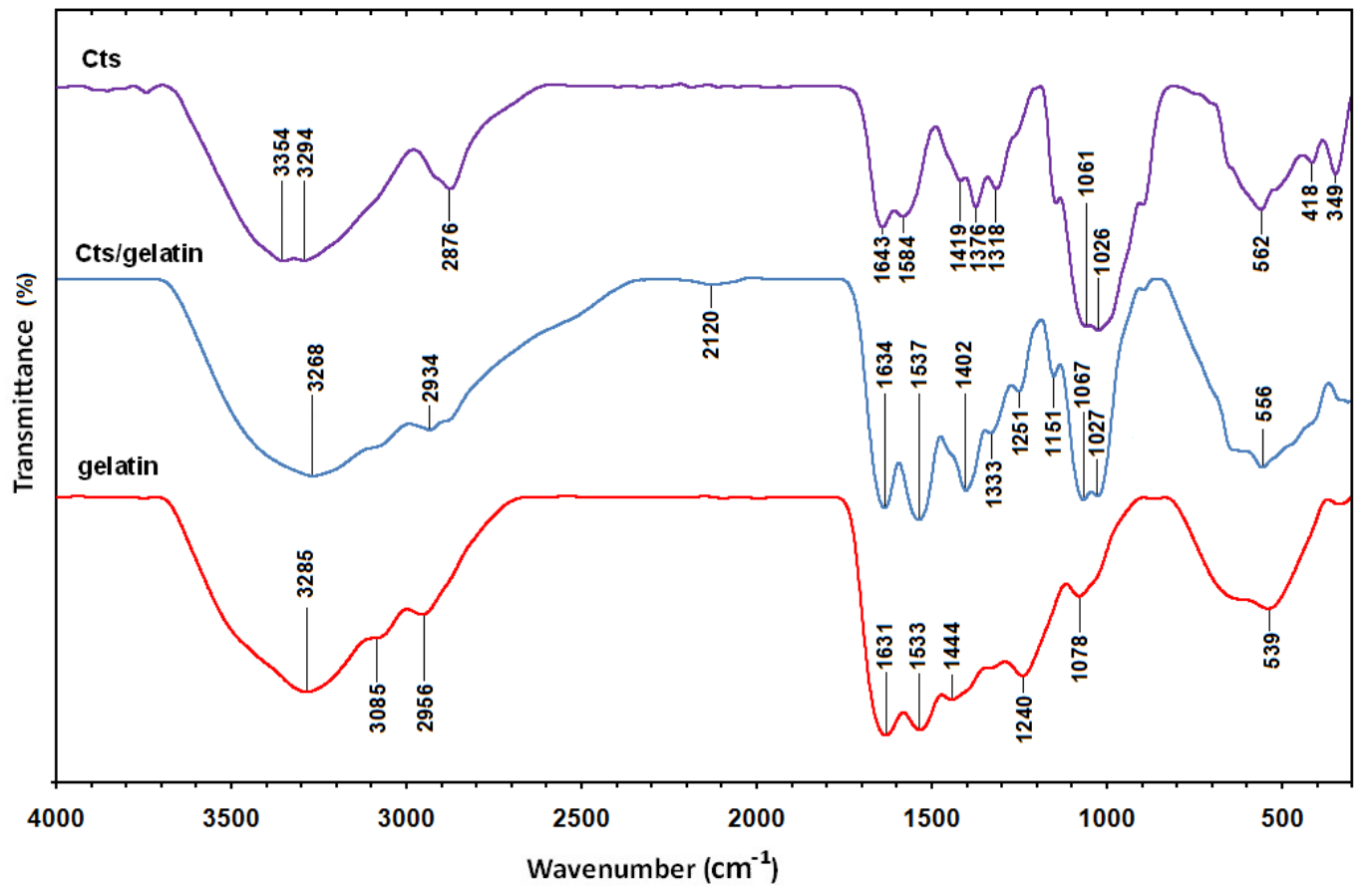


Figure 7. Fourier transform infrared spectra for the $\mathrm{Ag} / \mathrm{Cts}(\mathrm{S} 1), \mathrm{Ag} / \mathrm{Cts} /$ gelatin (S2) and Ag/gelatin (S3).

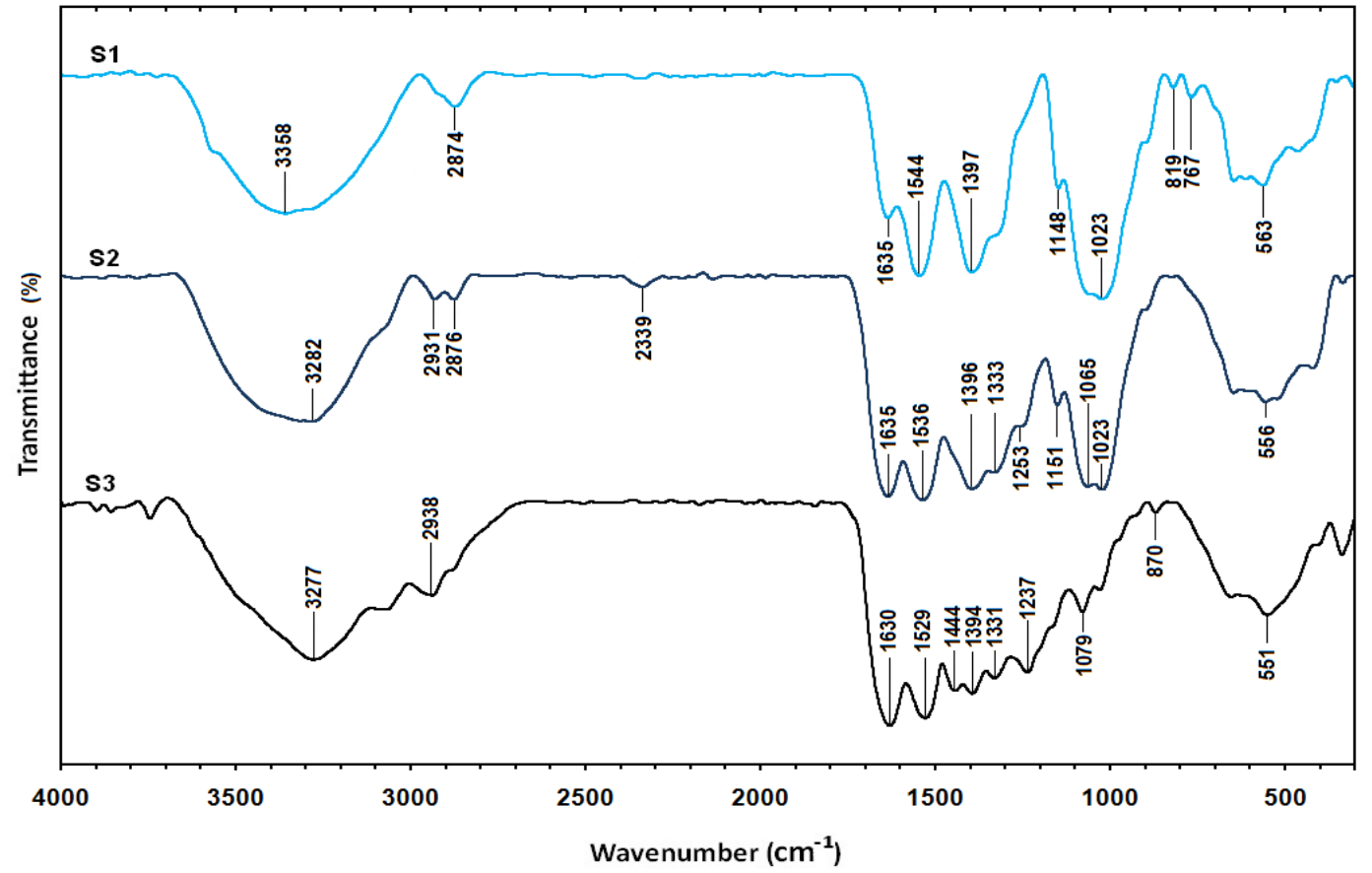

\subsection{Powder X-Ray Diffraction}

As shown in Figure 3, all the AgBNCs had a similar x-ray diffraction patterns. The PXRD peaks at $2 \theta$ with value of around $38^{\circ}, 44^{\circ}, 64^{\circ}$, and $77^{\circ}$ could be recognized to the $111,200,220$, and 311 crystallographic planes of the face-centered cubic Ag crystals, respectively [28]. For Ag/Cts BNCs, its PXRD profile showed peak at $37.97^{\circ}, 44.05^{\circ}, 64.21^{\circ}$ and $77.21^{\circ}$ related to AgNPs whereas peak at $21.80^{\circ}$ related to Cts. PXRD profile of $\mathrm{Ag} / \mathrm{Cts} /$ gelatin $\mathrm{BNCs}$ displayed peak at $22.53^{\circ}$ for Cts/gelatin, $28.04^{\circ}, 43.98^{\circ}, 64.17^{\circ}$ and $77.11^{\circ}$ for Ag. Lastly, the Ag/gelatin BNCs showed peak at $21.87^{\circ}$ for gelatin, $37.87^{\circ}, 43.91^{\circ}, 64.18^{\circ}$ and $76.88^{\circ}$ for $\mathrm{Ag}$ crystals structure. These results further confirmed the existence of AgNPs as final product in the Cts, Cts/gelatin and gelatin BNCs

\subsection{Morphology}

The TEM images of AgBNCs and the particle size distributions for $\mathrm{Ag} / \mathrm{Cts}, \mathrm{Ag} / \mathrm{Cts} / \mathrm{gelatin}$ and $\mathrm{Ag} /$ gelatin are shown in Figure 4. TEM images for those three samples revealed the mean diameters with standard deviation of the AgNPs about $10.50 \pm 2.99,3.37 \pm 0.86$, and $4.38 \pm 1.06 \mathrm{~nm}$ for $\mathrm{Ag} / \mathrm{Cts}$ (Figures 4A,B), Ag/Cts/gelatin (Figures 4C,D) and Ag/gelatin (Figures 4E,F), respectively. These results showed that the diameters of the AgNPs are the smallest in Cts/Gelatin suspension compared to Cts and Gelatin alone. In addition, the TEM image of $\mathrm{Ag} / \mathrm{Cts}$ showed some aggregation of AgNPs, whereas the TEM image of Ag/gelatin showed fewer AgNPs within the gelatin suspension. With the combination of both $\mathrm{Cts}$ and gelatin, the TEM image of $\mathrm{Ag} / \mathrm{Cts} /$ gelatin illustrated the good distribution and higher occurrence of the AgNPs.

Thin films of $\mathrm{Ag} / \mathrm{Cts}$ and $\mathrm{Ag} / \mathrm{gelatin}$ present different surface topography when analysed with AFM (Figures $5 \mathrm{~A}$ and $5 \mathrm{C}$ ). However the $\mathrm{Ag} / \mathrm{Cts} /$ gelatin film exhibits combination of both $\mathrm{Cts}$ and gelatin 
surface topography (Figure 5B). The AgBNCs film morphologies were dependent on several factors including polymer solubility, solvent evaporation, total thickness, molecular weight and surface composition [29].

\subsection{Fourier Transform Infrared Spectroscopy}

The Fourier transform infrared spectrum of Cts (Figure 6) shows vibration bands at 3354 and $3294 \mathrm{~cm}^{-1}$ due to overlapping of $\mathrm{O}-\mathrm{H}$ and amine $\mathrm{N}-\mathrm{H}$ stretching bands; a peak at $2876 \mathrm{~cm}^{-1}$ indicated aliphatic $\mathrm{C}-\mathrm{H}$ stretching; 1643 and $1584 \mathrm{~cm}^{-1}$ for $\mathrm{N}-\mathrm{H}$ bending; 1419, 1376, and $1318 \mathrm{~cm}^{-1}$ for $\mathrm{C}-\mathrm{H}$ bending; and 1061 and $1026 \mathrm{~cm}^{-1}$ for $\mathrm{C}-\mathrm{O}$ stretching [30]. The spectrum of gelatin (Figure 6) showed vibration bands at $3285 \mathrm{~cm}^{-1}$ for $\mathrm{N}-\mathrm{H}$ stretch coupled with hydrogen bonding (HB), $3085 \mathrm{~cm}^{-1}$ for alkenyl $\mathrm{C}-\mathrm{H}$ stretch, $2956 \mathrm{~cm}^{-1}$ for $\mathrm{CH}_{2}$ asymmetrical stretching, $1631 \mathrm{~cm}^{-1}$ for $\mathrm{C}=\mathrm{O}$ stretch/HB coupled with $\mathrm{COO}^{-}$, band at $1533 \mathrm{~cm}^{-1}$ for $\mathrm{N}-\mathrm{H}$ bend coupled with $\mathrm{CN}$ stretch, $1444 \mathrm{~cm}^{-1}$ for $\mathrm{CH}_{2}$ bend, $1240 \mathrm{~cm}^{-1}$ for $\mathrm{NH}$ bend, and $1078 \mathrm{~cm}^{-1}$ for $\mathrm{C}-\mathrm{O}$ stretch [31]. The spectra of Cts/gelatin composite showed a mixture of characteristic absorptions due to the amine groups of Cts and the carboxylic acid groups of gelatin. The amine group peaks for pure chitosan were shifted from 1643 and $1584 \mathrm{~cm}^{-1}$ to 1634 and $1537 \mathrm{~cm}^{-1}$ in Cts/gelatin composite, corresponding to the bend vibration of amine chitosan. The pure gelatin was characterized by an amino band at $1533 \mathrm{~cm}^{-1}$ and a carbonyl peak at $1631 \mathrm{~cm}^{-1}$ shifted to 1634 and $1537 \mathrm{~cm}^{-1}$ as well. The shifting of both amino and carbonyl bands in the spectra of Cts/gelatin composite showed the formation of complex involving $\mathrm{HB}$ in between chitosan and gelatin [23]. The spectrum of Ag/Cts BNCs (Figure 7) showed a blue shift of the Cts peaks at 1643 and $1584 \mathrm{~cm}^{-1}$ to 1635 and $1544 \mathrm{~cm}^{-1}$, respectively, and also displayed a high intensity peak at $1544 \mathrm{~cm}^{-1}$. The vibration band of $\mathrm{Ag} / \mathrm{Cts}$ at $1397 \mathrm{~cm}^{-1}$ could indicate the interaction between AgNPs with Cts. The spectrum of $\mathrm{Ag} / \mathrm{Cts} /$ gelatin BNCs (Figure 7) presented a narrower vibration band for the $\mathrm{O}-\mathrm{H}$ group at $3282 \mathrm{~cm}^{-1}$ compared to $\mathrm{Cts} /$ gelatin composite and also the interaction peak between $\mathrm{Ag}$ and $\mathrm{Cts} /$ gelatin at $1396 \mathrm{~cm}^{-1}$. In the spectrum of $\mathrm{Ag} / \mathrm{gelatin} \mathrm{BNCs}$, the occurrence of the vibration band at $1394 \mathrm{~cm}^{-1}$ it is also noted.

\section{Experimental}

\subsection{Materials}

All reagents in this work were of analytical grade and were used as received without further purification. $\mathrm{AgNO}_{3}$ (99.98\%) was used as the silver precursor, and was obtained from Merck (Darmstadt, Germany). Meanwhile, $\mathrm{NaBH}_{4}$, the reducing agent, was obtained from Sigma-Aldrich (St. Louis, MO, USA). Low molecular weight chitosan and glacial acetic acid $(99 \%)$ were also obtained from Sigma-Aldrich. The gelatin was obtained from HiMedia (Bombay, India). All the aqueous solutions were prepared with double-distilled water.

\subsection{Synthesis AgNPs in Chitosan BNC}

The chitosan suspension was prepared by solubilizing chitosan $(1.0 \mathrm{~g})$ in acetic acid $(50 \mathrm{~mL}, 1.0 \mathrm{wt} \%)$ solution. Then, $\mathrm{AgNO}_{3}(50 \mathrm{~mL}, 0.01 \mathrm{M})$ was added immediately into the suspension under constant stirring for 2.0 hours for preparation of the $\mathrm{AgNO}_{3}$ in chitosan suspension. $\mathrm{NaBH}_{4}(20 \mathrm{~mL}, 0.04 \mathrm{M})$ 
was added to the suspension of $\mathrm{AgNO}_{3} / \mathrm{Cts}$ and an immediate color change from pale yellow to brown indicating the formation of AgNPs was noted. This suspension was stirred for 1.0 hour more, then the obtained $\mathrm{Ag} / \mathrm{Cts} \mathrm{BNCs}$ were finally made into thin films for further characterization.

\subsection{Synthesis AgNPs in Chitosan/Gelatin BNC}

Chitosan (0.5 g) was dissolved in acetic acid $(25 \mathrm{~mL}, 1.0 \mathrm{wt} \%)$ solution. On the other hand, gelatin $(0.5 \mathrm{~g})$ was dissolved in warm $\left(40{ }^{\circ} \mathrm{C}\right)$ distilled water $(25 \mathrm{~mL})$. Next, both suspensions were mixed together and $\mathrm{AgNO}_{3}(50 \mathrm{~mL}, 0.01 \mathrm{M})$ was added directly into the suspensions. The $\mathrm{AgNO}_{3} / \mathrm{Cts} /$ gelatin suspension was stirred for 2.0 hours. The $\mathrm{NaBH}_{4}(20 \mathrm{~mL}, 0.04 \mathrm{M})$ was added immediately to the suspension of $\mathrm{AgNO}_{3} / \mathrm{Cts} /$ gelatin. A color change from colorless to dark brown was observed. The suspension was stirred for another 1.0 hour, then the obtained $\mathrm{Ag} / \mathrm{Cts} /$ gelatin BNCs were made into thin films for characterization.

\subsection{Synthesis AgNPs in Gelatin BNC}

For preparation of gelatin suspension, gelatin $(1.0 \mathrm{~g})$ was solubilized in warm $\left(40{ }^{\circ} \mathrm{C}\right)$ distilled water $(50 \mathrm{~mL})$. After that, $\mathrm{AgNO}_{3}(50 \mathrm{~mL}, 0.01 \mathrm{M})$ was mixed into the suspension and stirring continued for 2.0 hours. $\mathrm{NaBH}_{4}(20 \mathrm{~mL}, 0.04 \mathrm{M})$ was introduced immediately to the suspension of $\mathrm{AgNO}_{3}$ /gelatin. An immediate color change from colorless to light brown was observed. This suspension was stirred for 1.0 hour. The product was finally prepared in thin films for further characterization.

\subsection{Characterization Methods and Instruments}

The prepared Ag BNCs were characterized by UV-visible spectroscopy (UV-visible), powder X-ray diffraction (PXRD), transmission electron microscopy (TEM), atomic force microscopy (AFM), and Fourier transform infrared spectroscopy (FTIR). The UV-visible spectra were detected over the range of 300-700 nm using a Shimadzu H.UV.1650 PC UV-visible spectrophotometer. Crystalline structures of the synthesized Ag were examined using Philips X'pert Pro Panalytical PW3040MPD X-ray diffraction. TEM image observations were carried out on Hitachi H-7100 electron microscope and the particle size distributions were determined using the UTHSCSA Image Tool program (V. 3.00; University of Texas Health Science Center, San Antonio, TX, USA). FTIR spectra were recorded over the range of $300-4000 \mathrm{~cm}^{-1}$ using a Series 100 Perkin Elmer FT-IR 1650 spectrophotometer. The AFM image was obtained on an Ambios Q-scope (Ambios Technology, Santa Cruz, CA, USA) (SPM) machine.

\section{Conclusions}

AgNPs were successfully introduced into Cts, Cts/gelatin, and gelatin natural polymers using a chemical reduction method. This was confirmed by the maximum surface plasmon resonance peak at 408-414 nm for each sample indicating the formation of Ag NPs. The crystalline structures of AgNPs were found to be face centered cubic type. The average diameters of the AgNPs were revealed to be 10.50, 3.37 and $4.38 \mathrm{~nm}$ for $\mathrm{Ag} / \mathrm{Cts}, \mathrm{Ag} / \mathrm{Cts} /$ gelatin and $\mathrm{Ag} /$ gelatin, respectively. The best distribution 
of AgNPs was found to be in Cts/gelatin suspension and their average diameters were found to be the smallest from TEM results. Hence, we conclude that Cts/gelatin works better as stabilizer and size control compared to $\mathrm{Cts}$ and gelatin alone.

\section{Acknowledgments}

The authors are grateful to the staffs of the Department of Chemistry and the Institute of Bioscience, Universiti Putra Malaysia for technical assistance which led to the success of this research.

\section{References}

1. Tolaymat, T.M.; Badawy, A.M.E.; Genaidy, A.; Scheckel, K.G.; Luxton, T.P.; Suidan, M. An evidence-based environmental perspective of manufactured silver nanoparticle in syntheses and applications: A systematic review and critical appraisal of peer-reviewed scientific papers. Sci. Total Environ. 2010, 408, 999-1006.

2. Darder, M.; Colilla, M.; Ruiz-Hitzky, E. Chitosan-clay nanocomposites: Application as electrochemical sensors. Appl. Clay Sci. 2005, 28, 199-208.

3. Nair, L.S.; Laurencin, C.T. Silver nanoparticles: Synthesis and therapeutic applications. J. Biomed. Nanotechnol. 2007, 3, 301-316.

4. Rai, M.; Yadav, A.; Gade, A. Silver nanoparticles: A novel antimicrobial agent. Biotechnol. Adv. 2009, 27, 76-83.

5. Ahmad, M.B.; Shameli, K.; Darroudi, M.; Yunus, W.M.Z.W.; Ibrahim, N.A. Synthesis and characterization of silver/clay/chitosan bionanocomposites by UV-irradiation method. Am. J. Appl. Sci. 2009, 6, 2030-2035.

6. Gonzalez, C.M.; Liu, Y.; Scaiano, J.C. Photochemical strategies for the facile synthesis of gold-silver alloy and core-shell bimetallic nanoparticles. J. Phys. Chem. C 2009, 113, 11861-11867.

7. Darroudi, M.; Ahmad, M.B.; Shameli, K.; Abdullah, A.H.; Ibrahim, N.A. Synthesis and characterization of UV-irradiated silver/montmorillonite nanocomposites. Solid State Sci. 2009, $11,1621-1624$.

8. Ahmad, M.B.; Shameli, K.; Darroudi, M.; Yunus, W.M.Z.W.; Ibrahim, N.A. Synthesis and characterization of silver/clay nanocomposites by chemical reduction method. Am. J. Appl. Sci. 2009, 6, 1909-1914.

9. Yin, H.; Yamamoto, T.; Wada, Y.; Yanagida, S. Large-scale and size-controlled synthesis of silver nanoparticles under microwave irradiation. Mater. Chem. Phys. 2004, 83, 66-70.

10. Salkar, R.A.; Jeevanandam, P.; Aruna, S.T.; Koltypin, Y.; Gedanken, A. The sonochemical preparation of amorphous silver nanoparticles. J. Mater. Chem. 1999, 9, 1333-1335.

11. Jingquan, C.; Suwei, Y.; Weiguo, Z.; Zou, Y. Preparation and characterization of silver colloids with different morphologies under ultrasonic field. Front Chem. China 2006, 4, 418-422.

12. Huang, N.M.; Radiman, S.; Lim, H.N.; Khiew, P.S. $\gamma$-Ray assisted synthesis of silver nanoparticles in chitosan solution and the antibacterial properties. Chem. Eng. J. 2009, 155, 499-507.

13. Shin, H.S.; Yang, H.J.; Kim, S.B.; Lee, M.S. Mechanism of growth of colloidal silver nanoparticles stabilized by polyvinyl pyrrolidone in $\gamma$-irradiated silver nitrate solution. J. Colloid Interface Sci. 2004, 274, 89-94. 
14. Temgire, M.K.; Joshi, S.S. Optical and structural studies of silver nano-particles. Radiat. Phys. Chem. 2004, 71, 1039-1044.

15. Xu, G.N.; Qiao, X.L.; Qiu, X.L.; Chen, J.G. Preparation and characterization of stable monodisperse silver nanoparticles via photoreduction. Colloids Surf. A 2008, 320, 222-226.

16. Kong, H.; Jang, J. Antibacterial properties of novel poly(methyl methacrylate) nanofiber containing silver nanoparticles. Langmuir 2008, 24, 2051-2056.

17. Shameli, K.; Ahmad, M.B.; Yunus, W.M.Z.W.; Ibrahim, N.A.; Rahman, R.A.; Jokar, M.; Darroudi, M. Silver/poly (lactic acid) nanocomposites: Preparation, characterization, and antibacterial activity. Int. J. Nanomed. 2010, 5, 573-579.

18. Shervani, Z.; Ikushima, Y.; Sato, M.; Kawanami, H.; Hakuta, Y.; Yokoyama, T.; Nagase, T.; Kuneida, H.; Aramaki, K. Morphology and size-controlled synthesis of silver nanoparticles in aqueous surfactant polymer solutions. Colloid Polym. Sci. 2008, 286, 403-410.

19. Cao, X.L.; Cheng, C.; Ma, Y.L.; Zhao, C.S. Preparation of silver nanoparticles with antimicrobial activities and the researches of their biocompatibilities. J. Mater. Sci. Mater. Med. 2010, 21, 2861-2868.

20. Shih, C.M.; Shieh, Y.T.; Twu, Y.K. Preparation of gold nanopowders and nanoparticles using chitosan suspensions. Carbohydr. Polym. 2009, 78, 309-315.

21. Xu, X.; Zhou, M. Antimicrobial gelatin nanofibers containing silver nanoparticles. Fibers Polym. 2008, 9, 685-690.

22. Jayakumar, R.; Menon, D.; Manzoor, K.; Nair, S.V.; Tamura, H. Biomedical applications of chitin and chitosan based nanomaterials-A short review. Carbohydr. Polym. 2010, 82, 227-232.

23. Mi, F.L. Synthesis and characterization of a novel chitosan-gelatin bioconjugate with fluorescence emission. Biomacromolecules 2005, 6, 975-987.

24. Chen, J.P.; Lim, L.L. Key factors in chemical reduction by hydrazine for recovery of precious metals. Chemosphere 2002, 49, 363-370.

25. Aihara, N.; Torigoe, K.; Esumi, K. Preparation and characterization of gold and silver nanoparticles in layered laponite suspensions. Langmuir 1998, 14, 4945-4949.

26. Peng, S.; McMahon, J.M.; Schatz, G.C.; Gray, S.K.; Sun, Y. Reversing the size-dependence of surface plasmon resonances. Proc. Natl. Acad. Sci. USA 2010, 107, 14530-14534.

27. Liu, Y.; Chen, S.; Zhong, L.; Wu, G. Preparation of high-stable silver nanoparticle dispersion by using sodium alginate as a stabilizer under gamma radiation. Radiat. Phys. Chem. 2009, 78, 251-255.

28. Shameli, K.; Ahmad, M.B.; Zargar, M.; Yunus, W.M.; Ibrahim, N.A.; Shabanzadeh, P.; Moghaddam, M.G. Synthesis and characterization of silver/montmorillonite/chitosan bionanocomposites by chemical reduction method and their antibacterial activity. Int. J. Nanomed. 2011, 6, 271-284.

29. Puiso, J.; Prosycevas, I.; Guobiene, A.; Tamulevicius, S. Plasmonic properties of silver in polymer. Mater. Sci. Eng. B 2008, 149, 230-236.

30. Osman, Z.; Arof, A.K. FTIR studies of chitosan acetate based polymer electrolytes. Electrochimica Acta 2003, 48, 993-999. 
31. Muyonga, J.H.; Cole, C.G.B.; Duodu, K.G. Fourier transform infrared (FTIR) spectroscopic study of acid soluble collagen and gelatin from skins and bones of young and adult Nile perch (Lates niloticus). Food Chem. 2004, 86, 325-332.

Sample Availability: Samples of the compounds are available from the authors.

(C) 2011 by the authors; licensee MDPI, Basel, Switzerland. This article is an open access article distributed under the terms and conditions of the Creative Commons Attribution license (http://creativecommons.org/licenses/by/3.0/). 